\title{
Large-scale dust event in East Asia, as revealed by the Himawari-8 DUST RGB, lidar network observations, and field survey
}

\author{
Kenji Kai ${ }^{1, *}$, Yuki Minamoto ${ }^{2}$, Kotaro Nakamura ${ }^{3}$, Minrui Wang $^{2}$, Kei Kawai ${ }^{2}$, Kazuma Ohara $^{2}$, \\ Jun $\mathrm{Noda}^{4}$, Teruya Maki ${ }^{5}$, E. Davaanyam ${ }^{6}$, and Nobuo Sugimoto ${ }^{7}$ \\ ${ }^{1}$ Ibaraki University, 2-1-1 Bunkyo, Mito, Ibaraki 310-8512, Japan \\ ${ }^{2}$ Nagoya University, Furo-cho, Chikusa-ku, Nagoya, Aichi 464-8601, Japan \\ ${ }^{3}$ Japan Meteorological Agency, Chiyoda-ku, Tokyo, 100-8122, Japan \\ ${ }^{4}$ Rakuno Gakuen University, Ebetsu, Hokkaido 069-8501, Japan \\ ${ }^{5}$ Kanazawa University, Kakuma, Kanazawa, Ishikawa 920-1192, Japan \\ ${ }^{6}$ Information and Research Institute of Meteorology, Hydrology and Environment, Ulaanbaatar 210646, Mongolia \\ ${ }^{7}$ National Institute for Environmental Studies, Tsukuba, Ibaraki, 305-8506, Japan
}

\begin{abstract}
A large-scale dust event occurred in East Asia during early May 2017, and transported dust was measured all over Japan. We performed an analysis of the entire dust event using multiple sources: a local ceilometer measurement, measurements from an optical particle counter in the Gobi Desert (Dalanzadgad, Mongolia), a study of Dust RGB imagery obtained from Himawari-8, lidar measurements from Japan, and meteorological data. Our results show that three extratropical low pressure systems occurred consecutively in Mongolia and generated dust storms in the Gobi Desert. Remarkably, the Dust RGB imagery shows both the occurrence and the transportation of the dust, and was able to detect two dust outbreaks in the Horqin Sandy Land of Northern China and their transportation to eastern Japan; this shows that the Horqin Sandy Land was one of the source regions of this dust event.
\end{abstract}

\section{Introduction}

Dust events that mainly occur in arid and semiarid areas in East Asia during spring, and are subsequently transported to eastern China, and Japan are generally called "Asian dust" [1-3]. The main arid and semiarid regions in East Asia are shown in Fig. 1. Among them, the Gobi Desert, the Taklimakan Desert, and the Loess Plateau have been focused on and studied as the main source regions of Asian dust in recent years [4-6]. In addition, the Horqin Sandy Land, which is located between the Inner Mongolia Plateau and the Northeast China Plain, has suffered rapid desertification due to human activity, and the arid areas (considered to be the source regions of dust events) have expanded during recent decades [7-9].

The dust outbreak frequency in the Gobi Desert was high before 2006, but slowed after 2008 [10]. The number of days in which dust events were detected in Japan also decreased significantly after 2011, when compared with the number detected in the years before 2010 [11]. Nevertheless, 46 of 59 dust observation stations in Japan reported the presence of transported dust on 7 May 2017. This was the largest dust event that occurred in Japan since the event on 21 May 2010.
Furthermore, it was the only dust transport event in recent years that affected all of the Japanese islands.

Coincidentally and fortunately, the dust event took place during our field work to measure the dust outbreak in Dalanzadgad, Mongolia [12], which is located in the Gobi Desert (Fig. 1). This allowed us to do an overall analysis of the event, from the beginning of the dust outbreak in the Gobi Desert and its surrounding areas to the end of the transportation of the dust in Japan. Our work contains a ceilometer observation in Dalanzadgad,

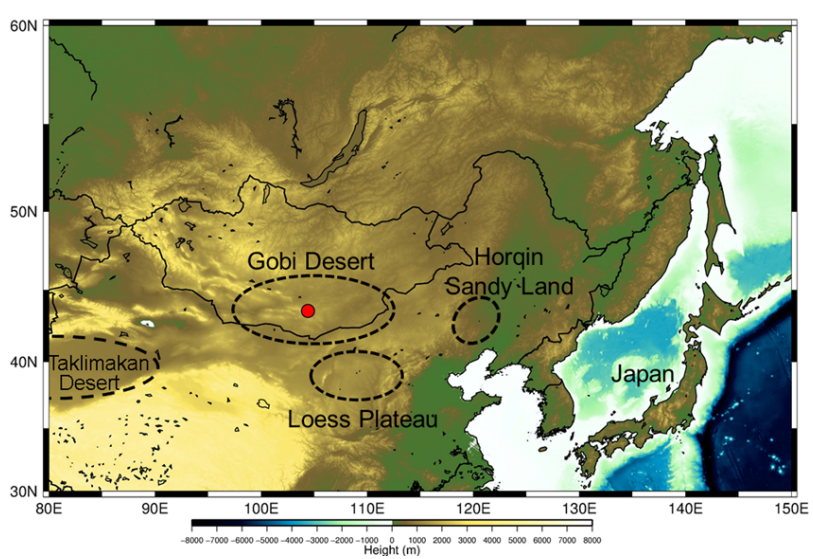

Fig. 1. Map of the main arid and semiarid regions in East Asia The red circle represents the location of Dalanzadgad [12].

\footnotetext{
Corresponding author: kenji.kai.kk@vc.ibaraki.ac.jp
} 
analysis of Himawari-8 satellite data, and multiple other observations and analyses. In this study, we elucidate the mechanism of dust occurrence, as well as the detailed process of dust transportation during this event.

\section{Observations and data}

A ceilometer observation has been conducted in the central part of the Gobi Desert since 29 April 2013 [13]. The observation site is the Dalanzadgad Meteorological Observatory $\left(43.58^{\circ} \mathrm{N}, 104.42^{\circ} \mathrm{E}, 1470 \mathrm{~m}\right.$ above sea level) in southern Mongolia (Fig. 1). The ceilometer located there is model Vaisala CL51, which is a compact backscatter lidar using a laser wavelength of $910 \mathrm{~nm}$ with time and height resolutions of $6 \mathrm{~s}$ and $10 \mathrm{~m}$, respectively. We measured dust concentration on the ground in Dalanzadgad by using an optical particle counter (OPC) every $30 \mathrm{~min}$ from 04 UTC on 1 May to 11 UTC on 3 May, 2017.

To trace the transport routes of the dust, we analyzed Dust RGB imagery derived from composite data of Himawari-8, which is a new-generation Japanese geostationary meteorological satellite [14]. The Dust RGB imagery was created from Bands $11(8.6 \mu \mathrm{m}), 13$ $(10.4 \mu \mathrm{m})$, and $15(12.4 \mu \mathrm{m})$ of the Advanced Himawari Imagers onboard the satellite; these bands are based on different characteristics of absorption and scattering in the infrared wavelengths between dust and cloud [15]. Dust can be detected during both day and night with horizontal and temporal resolutions of $0.02^{\circ} \times 0.02^{\circ}$ and $10 \mathrm{~min}$, respectively. We also obtained GDAS/FNL 0.25 Degree Global Tropospheric Analyses and Forecast Grid data, which is a three-dimensional grid of meteorological data produced by the National Centers for Environmental Prediction (NCEP) in the United States. The horizontal and temporal resolutions of the data are $0.25^{\circ} \times 0.25^{\circ}$ and $3 \mathrm{~h}$ (analysis + forecast), respectively.

We utilized data of two lidar observations in Sapporo and Nagasaki, Japan, which belong to the Asian Dust and Aerosol Lidar Observation Network (AD-Net) [16]. The concentration of suspended particulate matter (SPM; corresponding approximately to PM7) on the ground

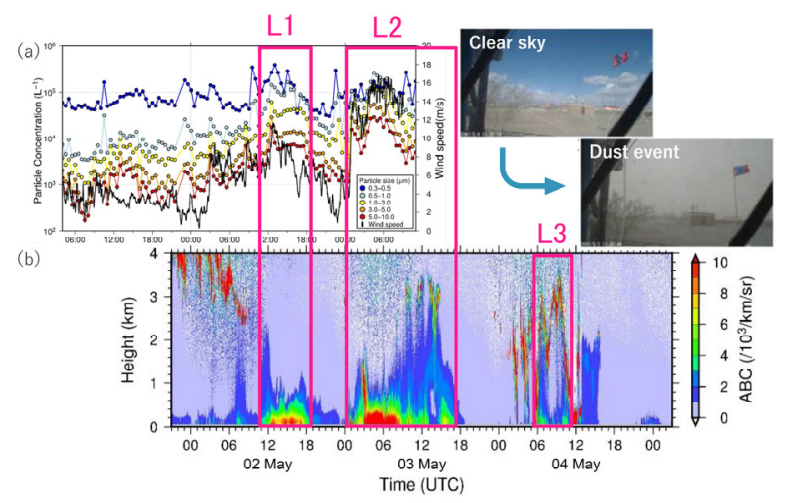

Fig. 2. (a) Time series of the size-resolved number concentration measured OPC and wind speed, and (b) the attenuated backscatter coefficient observed by the ceilometer in Dalanzadgad in May 2017. near each of the lidar observation sites were derived from Atmospheric Environmental Regional Observation System (AEROS) tentative data, which is managed by the Ministry of the Environment.

\section{Results}

A large-scale dust event occurred in East Asia during 2-8 May 2017. Three extratropical low pressure systems passed arid and semiarid regions in inland East Asia consecutively, and emitted dust from multiple source regions intermittently. Hereafter, the three low pressure systems are called L1, L2, and L3 in the order of their generation. The dust generated by L3, in particular, was transported throughout Japan by the cold front and two troughs that were associated with L3.

\subsection{Dust emission and transportation due to L1}

At 00 UTC on 2 May, low pressure system L1 occurred over central Mongolia with a cold front, which extended southward from the L1 center. In the rear (west) of the cold front, westerly winds were dominant. During 06-15 UTC on 2 May, the cold front passed the Gobi Desert, and the first dust storm occurred in a region of strong westerly winds ( $\geq 10 \mathrm{~m} / \mathrm{s}$ ) (Fig. 2). The dust storms are shown by large attenuated backscatter coefficients $\left(\geq 3 \times 10^{-3} / \mathrm{km} / \mathrm{sr}\right)$, and the top of the dust storm exceeded $1.0 \mathrm{~km}$. During the dust storm, the wind speed was $6.5 \mathrm{~m} / \mathrm{s}$, and the number concentration of 1$10 \mu \mathrm{m}$ dust particles exceeded $5 \times 10^{3} / \mathrm{L}$. Then, L1 moved northeastward and strengthened, and the cold air mass behind the cold front transported the dust. At 21 UTC on 3 May, L1 dissipated in Amur Oblast, Russia.

\subsection{Dust emission and transportation due to L2}

Fig. 3 shows a dust RGB imagery with sea level pressure (contours; every $4 \mathrm{hPa}$ ) and surface wind during at 12:00 UTC on 3 May 2017. In the Dust RGB imagery, pink indicates dust, whereas yellow, brown, green, and black show clouds. At 03 UTC on 3 May, low pressure system L2 was generated in the cold air mass behind the cold front of L1. L2 moved northeastward and strengthened as L1 did. During 03-18 UTC on 3 May, strong winds of more than $15 \mathrm{~m} / \mathrm{s}$ blew widely on the southwestern side of the L2 center, and caused the second dust storm in the Gobi Desert (Fig. 2). The dust was lifted to a height of $1.0-2.0 \mathrm{~km}$. At $01 \mathrm{UTC}$, the wind speed suddenly increased to $14 \mathrm{~m} / \mathrm{s}$, and the number concentration of $1-10 \mu \mathrm{m}$ dust particles reached $1 \times 10^{4} / \mathrm{L}$ (Fig. 2). The dust moved eastward with the cold air mass behind the cold front. In northern and northeastern China, blowing and floating dust were reported when L2 passed. At 12 UTC on 5 May, L2 dissipated around Khabarovsk, Russia, and the dust reached the Sea of Okhotsk. 


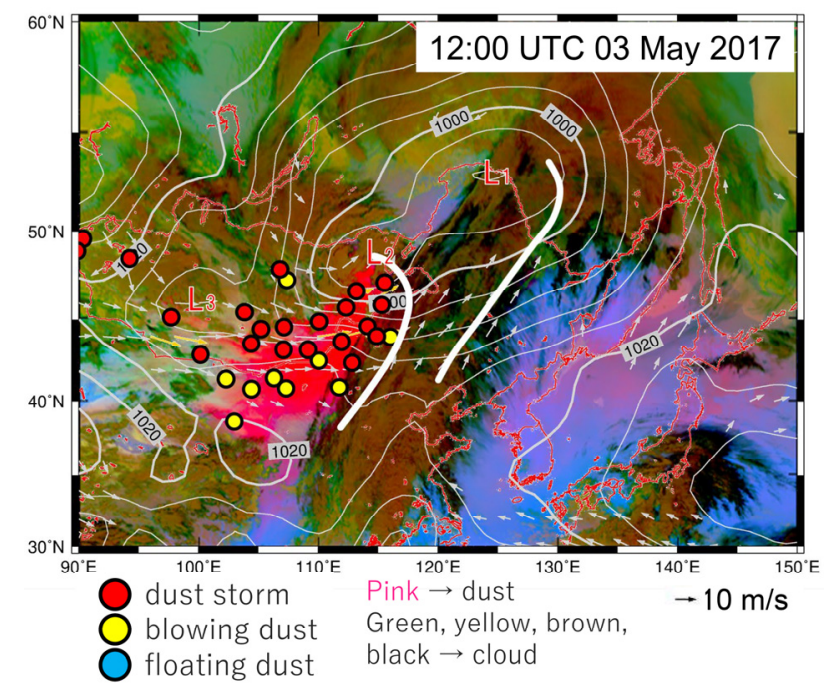

Fig. 3. Dust RGB imagery with sea level pressure (contours; every $4 \mathrm{hPa}$ ) and surface wind at 12:00 on 3 May 2017. In the Dust RGB imagery, pink indicates dust, whereas yellow, brown, green, and black show clouds. The white lines represent cold fronts.

\subsection{Dust emission and transportation due to L3}

Fig. 4 shows a dust RGB imagery with sea level pressure and surface wind during at 03:00 UTC on 6 May 2017. The dust emission due to low pressure system L3 can be divided into three dust masses, which were generated and transported to Japan by L3 and associated troughs $\mathrm{T} 3 \mathrm{a}$ and T3b. The first mass contained dust particles generated from both the Gobi Desert and the Horqin Sandy Land, and transported to eastern Japan. The second mass was generated from the Horqin Sandy Land, and finally transported to eastern Japan. The third mass was generated from the Gobi Desert, and approached the Loess Plateau during its transportation to western Japan.

Fig. 5 shows positions and courses of low pressure system L3 from 3 to 8 May 2017. It is clear that the cold

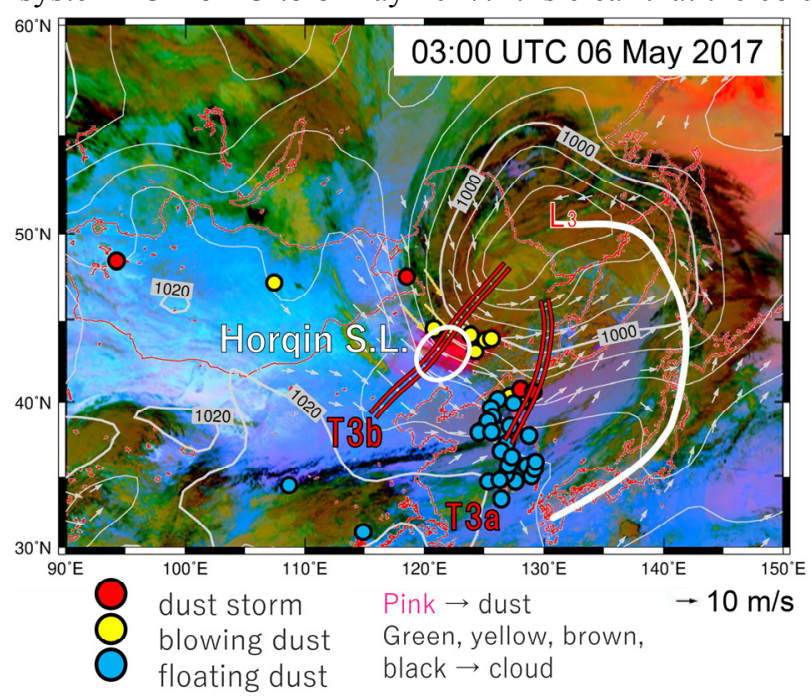

Fig. 4. Same as Fig. 3, but for 03:00 on 6 May 2017. The double red lines show troughs. The white circle shows the location of the Horqin Sandy Land.

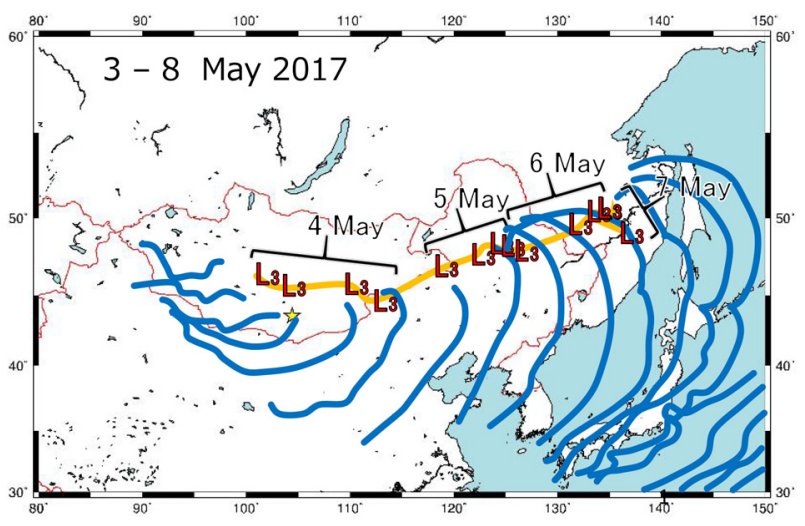

Fig. 5. Positions and courses of the low low pressure system L3 from 3 to 8 May 2017.

air mass, along with L3, lifted the dust particles from not only the Gobi Desert, but also the Horqin Sandy Land, and eventually transported them to eastern Japan. Hence, this dust event suggests that the Horqin Sandy Land is also one of the source regions of Asian dust. Our data analysis and the Himawari-8 Dust RGB imagery clearly indicate the occurrence and transportation of dust from the Horqin Sandy Land, which has not been focused on or considered as a source region of Asian dust in previous research.

\section{Horqin Sandy Land as a source of dust storms}

The Gobi and Taklimakan Deserts and Loess Plateau are internationally well known as a dust source, but the Horqin Sandy Land (HSL) is not familiar with us. The HSL is one of the major aeolian sandy lands in the northeast China (total area $51,750 \mathrm{~km} 2 ; 118.58-123.5^{\circ} \mathrm{E}$, $42.68-45.25^{\circ} \mathrm{N} ; 178.5-631.9 \mathrm{~m}$ above sea level) [17]. It is the mixture of sand dune and interdune swales. The name of Horqin is originated from Jöči Qasar, a brother of Genghis Khan. The climate is a monsoon-influenced, continental steppe climate, characterized frequent drought and strong winds in spring. The annual precipitation of $350-450 \mathrm{~mm}$. The sandy surface is eroded by strong winds in winter and spring.

At late 20 century, the HSL was developed due to population growth. Sandy and grass lands were cultivated and over-pastured. The desertification was going on, and the ecosystem of HSL was degraded. Decertified lands have spread rapidly in the past three decades and new dust storm sources are expanding. Historically, the HSL was grasslands during a low population, and became deserts during a high population. The national policy of returning farmland to forest and grassland by the Chinese Government has started since 1998.

We recognized that the HSL is one of the important sources of the Asian dust [12]. The first author was interested in the Horqin Workshop on Ecological Vulnerability Assessment, held by Sustainable Development Institute for Western Region of Mongolia and Green Network (NPO) in Tongliao, Inner Mongolia, China during 5-9 July 2018 (Fig. 6). He attended the 


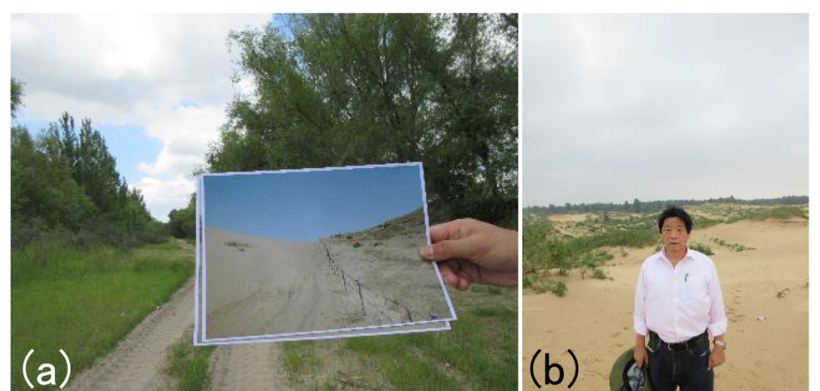

Fig. 6. Horqin Sandy Land (July 2018). (a) Afforestation project by NPO. The photo was taken 10 years ago. (b) K. Kai at a mobile sand dune in Horqin Sandy Land.

workshop and visited the HSL during the field seminar. He was impressed with tree planting at a moving sand dune to prevent the desertification in Horqin. Desertification is proceeding in the west side of HSL.

\section{Conclusion}

The dust event that occurred in early May 2017 was a special case because three extratropical low pressure systems with cold fronts and troughs passed the Gobi Desert consecutively, which transported dust to areas that cover a wide range of East Asia, including the Japanese islands. In Dalanzadgad, the dust storm occurred when the low pressure systems passed, resulting in high values from the ceilometer and OPC measurements. Moreover, L3 lifted dust particles, not only from the Gobi Desert, but also from the Horqin Sandy Land, which it then transported to all of the Japanese islands. So far, researchers mainly consider the Gobi Desert, the Taklimakan Desert, and the Loess Plateau as source regions of Asian dust. However, this study clearly suggests that the Horqin Sandy Land should be considered a source region of Asian dust as well (Fig. 6). This was validated by the two dust outbreaks generated by the passage of the cold front and T3b of L3 in the Horqin Sandy Land, during 06 to 09 UTC on 5 May and 01 to 09 UTC on 6 May, respectively.

Moreover, the Dust RGB imagery shows the presence of dust outbreaks that occurred in desertified areas (such as the Horqin Sandy Land). Hence, it is necessary for Asian dust researchers to give attention to such areas, which exhibit desertification caused by human activity (Fig. 6).

Acknowledgements: This study was supported by Grant-inAids for Scientific Research (No. 16H02703, No. 17H01616). The ceilometer and OPC observations in Dalanzadgad were supported by the Dalanzadgad Meteorological Observatory. The Himawari-8 data were provided by the Center for Environmental Remote Sensing, Chiba University: http://www.cr.chiba-u.jp/databases/GEO/H8 9/FD/index.html. The AD-Net lidar data were provided by the National Institute for Environmental Studies (http://www-lidar.nies.go.jp/AD$\underline{\mathrm{Net} / \text { ). }}$

\section{References}

1. K. Kai, Y. Okada, O. Uchino, I. Tabata, H. Nakamura, T. Takasugi, and Y. Nikaidou, J. Meteor. Soc. Japan, 66, 457-472 (1988)

2. R. B. Husar et al., J. Geophys. Res., 106, $18317-$ 18330 (2001)

3. I. Uno, K. Eguchi, K. Yumimoto, T. Takemura, A. Shimizu, M. Uematsu, Z. Liu, Z. Wang, Y. Hara, and N. Sugimoto, Nature Geosci., 2, 557-560 (2009)

4. J. Sun, M. Zhang, and T. Liu, J. Geophys. Res., 106, 10325-10333 (2001)

5. Y. Kurosaki, and M. Mikami, J. Meteor. Soc. Japan, 83A, 1-18 (2005)

6. J. Wu, Y. Kurosaki, M. Shinoda, and K. Kai, SOLA, 12, 187-192 (2016)

7. F. Li, L. Zhao, H. Zhang, T. Zhang, and Y. Shirato, Soil \& Tillage Research, 75, 121-130 (2003)

8. H. Zhao, R. Zhou, T. Zhang, and X. Zhao, Soil \& Tillage Research, 87, 175-185 (2005)

9. X. Zuo, H. Zhao, X. Zhao, Y. Guo, J. Yun, S. Wang, and T. Miyasaka, Environ. Geol., 58, 1227-1237 (2008)

10. J. $\mathrm{Wu}$, and K. Kai, 2016: Journal of Arid Land Studies, 26, 51-57 (2016)

11. Japan Meteorological Agency, The number of Kosa (Asian dust) observations in Japan from 1967 to 2016 (in Japanese). Available on http://www.data.jma.go.jp/gmd/env/kosahp/kosa_ta ble_1.html (2017)

12. M. Minamoto et al., SOLA, 14, 33-38 (2018)

13. K. Kawai, K. Kai, Y. Jin, N. Sugimoto, and D. Batdorj, SOLA, 11, 156-159 (2015)

14. K. Bessho, et al., J. Meteor. Soc. Japan, 94, 151-183 (2016)

15. Meteorological Satellite Center, Dust RGB Detection of Yellow Sand (Asian Dust). Available on http://www.data.jma.go.jp/mscweb/en/VRL/ VLab_RGB/RGBimage.html (2015)

16. N. Sugimoto, T. Nishizawa, A. Shimizu, I. Matsui, and Y. Jin, Proc. SPIE, 9262, 92620K (2014)

17. V.R. Squires, Rangeland degradation and recovery in China's pastoral lands, CAB International, 264p (2009) 